\title{
An Investigation on Strength Development of Cement with Cenosphere and Silica Fume as Pozzolanic Replacement
}

\author{
K. Senthamarai Kannan, ${ }^{1}$ L. Andal, ${ }^{2}$ and M. Shanmugasundaram ${ }^{3}$ \\ ${ }^{1}$ Department of Civil Engineering, Syed Ammal Engineering College, Ramanathapuram, Tamil Nadu 623502, India \\ ${ }^{2}$ Department of Civil Engineering, Velammal College of Engineering and Technology, Madurai, Tamil Nadu 625009, India \\ ${ }^{3}$ Department of Civil Engineering, Valliammai Engineering College, Kancheepuram, Tamil Nadu 603203, India
}

Correspondence should be addressed to K. Senthamarai Kannan; ksk1kannan@gmail.com

Received 22 February 2016; Revised 24 April 2016; Accepted 24 May 2016

Academic Editor: Ana S. Guimarães

Copyright (c) 2016 K. Senthamarai Kannan et al. This is an open access article distributed under the Creative Commons Attribution License, which permits unrestricted use, distribution, and reproduction in any medium, provided the original work is properly cited.

In the detailed study presented in this paper, an attempt was made to study the strength of cement when cenosphere (CS) and silica fume (SF) were used as replacement. Tests were carried out on mix with cenosphere as replacement for cement which has $12 \%$ of constant replacement of silica fume to the mass of cement, and this is made to stabilize the strength which was lost due to addition of cenosphere. From the test results, it was concluded that the strength loss of binder due to replacement of cenosphere can be stabilized by silica fume and still a safe value of strength can be achieved. Furthermore, the strength reduction is due to the consumption of hydration products and cloggy microstructure as observed in this study.

\section{Introduction}

A cenosphere is a lightweight, hollow sphere made largely of silica and alumina and filled with air, metals, or gas. The cenosphere was produced as a byproduct of coal combustion at thermal power plants. Blanco et al. [1] used powder-packing principle to produce lightweight concrete with cenospheres as primary "aggregate." With this cenosphere, an ultralightweight concrete can be manufactured with $1430 \mathrm{~kg} / \mathrm{m}^{3}$ with compressive strength of $60 \mathrm{MPa}$ [2]. It was also found that the surface modification of cenospheres accompanied by compatibilization led to the substantial improvement of mechanical properties and thermal stability of the composites [3]. The mechanical properties of polymer-cenospheres composites are inferior owing to poor interfacial interactions between the hydrophilic cenospheres surface and the hydrophilic polymer [4]. Thus, tetrasulphane modified cenosphere can be used as reinforcing filler [5]. It was found that cenospheres were not deleterious due to alkali silica reaction; also, fine cenospheres showed limited pozzolanic reactivity at $28-30^{\circ} \mathrm{C}$ and $38^{\circ} \mathrm{C}$ but exhibited significant pozzolanic reactivity at $80^{\circ} \mathrm{C}$ with aluminum tobermorite $\left[\mathrm{Ca}_{5} \mathrm{Si}_{5} \mathrm{Al}(\mathrm{OH}) \mathrm{O}_{17} \cdot 5 \mathrm{H}_{2} \mathrm{O}\right]$ and this was identified as the main reaction product [6]. The cenosphereconcrete composites show a structure of disintegrated pores, leading to low permeability; the pores were also found in the range of 2 to 5 micron meter [7]. The lightweight concrete prepared with powder-packing theory in order to obtain concrete with the lowest possible density was tested and the results show the loss of resistance to compression in dependence on density [1]. Cenospheres in fly ash-cement systems appear to act as energy-dissipating inclusions in fracture and do not necessarily weaken the system [8]. As for a matrix to maintain the strength of binding material, we had used silica fume. Silica particles with the size from $100 \mathrm{~nm}$ to $2 \mu \mathrm{m}$ were chosen [9]. In addition, silica is known to be used in construction industry to increase the strength of concrete as microfiller and a reactant in pozzolanic reaction during cement hydration [10]. It was proved that silica fume with $5 \%, 10 \%$, and $12 \%$ of replacement with an adequate amount of super plasticizer and W/B ratio improves the properties of cement grout [11]. It was also proved that addition of finer particles will ensure higher durability [12]. In the present study, the effect of cenosphere along with silica fume on the properties of binding material was investigated. 
TABle 1: Properties of cement, cenosphere, and silica fume.

(a)

\begin{tabular}{lccc}
\hline & \multicolumn{3}{c}{ Physical properties } \\
& Cement & Cenosphere & Silica fume \\
\hline $\begin{array}{c}\text { Blaine surface } \\
\text { Area }\left(\mathrm{m}^{2} / \mathrm{Kg}\right)\end{array}$ & 380 & 320 & 1500 \\
$\begin{array}{l}\text { Particle mean } \\
\text { Dia }(\mu \mathrm{m})\end{array}$ & $<32$ & $<100$ & $<1$ \\
Specific gravity & 3.1 & 0.9 & 2.3 \\
Loss of ignition & $2 \%$ & $1.30 \%$ & - \\
\hline
\end{tabular}

(b)

\begin{tabular}{|c|c|c|c|}
\hline & \multicolumn{3}{|c|}{ Chemical properties } \\
\hline & Cement & Cenosphere & Silica fume \\
\hline $\mathrm{SiO}_{2}$ & $23 \%$ & $65.00 \%$ & $89.00 \%$ \\
\hline $\mathrm{Al}_{2} \mathrm{O}_{3}$ & $4.20 \%$ & $36.00 \%$ & $10 \%$ \\
\hline $\mathrm{MgO}$ & $0.20 \%$ & $2.50 \%$ & - \\
\hline $\mathrm{Fe}_{2} \mathrm{O}_{3}$ & $1.20 \%$ & $3.00 \%$ & $2 \%$ \\
\hline $\mathrm{CaO}$ & $63 \%$ & $0.50 \%$ & $0.45 \%$ \\
\hline
\end{tabular}

\section{Materials and Experimental Investigation}

2.1. Materials Used in This Study. Ordinary Portland cement conforming to IS: 12269 (Indian Standard Designation, IS: 12269-1987) was used for this study. River sand obtained from Tamil Nadu Minerals Limited (State Government of Tamil Nadu) with specific gravity of 2.65 and fineness modulus of 2.64 was used as fine aggregate. In the present investigation, potable water was used. The cenospheres used in this study were obtained from Ash Tech, and Elkem silica fume was used. The properties of cement, cenosphere, and silica fume were given in Table 1.

2.2. Experimental Methods for Investigation. The mortar cubes were prepared with 1:3 of cement: fine aggregate ratio and water/binder ratio was fixed as 0.45 ; with this proportion, the mortars were prepared using mortar mixing machines. The cenosphere was used as replacement to cement up to $30 \%$ by weight of cement and the details of replacement were presented in Table 2. The mortar cubes of size $70.6 \mathrm{~mm} \times$ $70.6 \mathrm{~mm} \times 70.6 \mathrm{~mm}$ conforming to IS: $10080-1982$ were tested for compressive strength at 7 days, 14 days, and 28 days of age. Each layer is well compacted by a tamping rod of $12 \mathrm{~mm}$ diameter. After the compaction, the top surface is levelled using a trowel and left for 24 hours to dry in room temperature of $31^{\circ} \mathrm{C}$ with $75 \%$ humidity. On the next day, at room temperature of $30^{\circ} \mathrm{C}$ and $60 \%$ humidity, the mortar cubes are kept inside a curing tank filled with potable water. The specimens are tested with a $2000 \mathrm{kN}$ capacity hydraulic compression testing machine, as per IS: 4031-1982 (Part 6).

The specimens were also studied by scanning electron microscopy and XRD Patterns. Samples for scanning electron microscopy (SEM) analysis are taken near the surface (0$1 \mathrm{~mm}$ depth) of specimens. Microstructural studies utilized

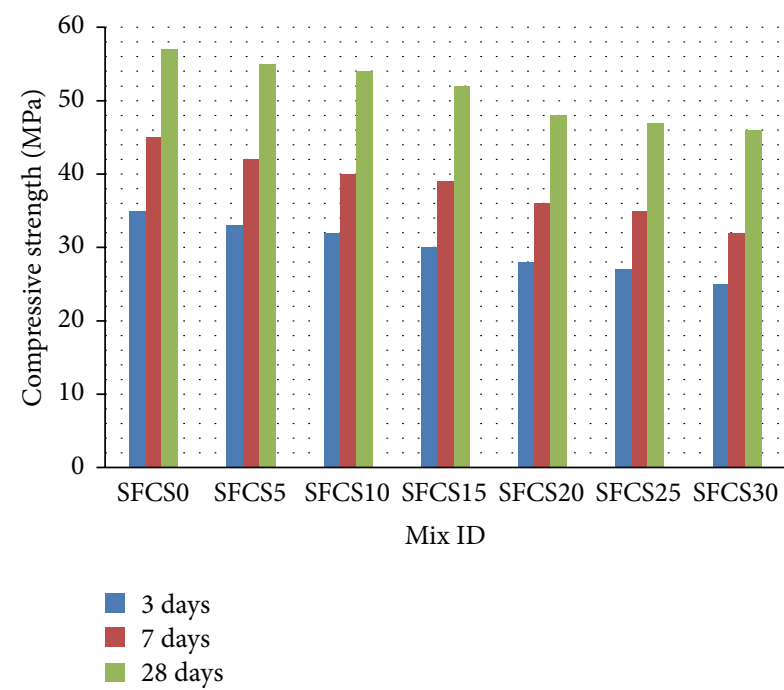

Figure 1: Compressive strength of mortar cubes.

SEM (Hitachi S-3000H, Japan) equipped with EDAX analyzer for microstructural observations of the surfaces, which is coated with evaporated copper for examination. A SEM analysis is done at a maximum magnification of 5000x with energy $20 \mathrm{keV}$ and a high resolution of $3.5 \mathrm{~nm}$. For this analysis, samples of size $10 \mathrm{~mm}$ cubes are cut with a saw cutter on 28th day. The XRD analysis is carried out with a Siemens $\mathrm{D}-5000 \mathrm{X}$-ray diffractometer with $\mathrm{Cu} \mathrm{K}$-beta radiation and 2 scanning with a step size of $0.02^{\circ}$ and a measuring time of $10.00 \mathrm{Deg} / \mathrm{minute}$. A voltage of $40 \mathrm{kV}$ and current of $15 \mathrm{~mA}$ are used. Samples are collected from the cubes after 28 days of water curing and powdered in ball mills to pass through the sieve size of $90 \mu$.

\section{Results and Discussions}

3.1. Compressive Strength of Mortar Cubes. At 3 days, 7 days, and 28 days, the mortar cubes strength were tested and the results were discussed in Table 2 and Figure 1. The results show that the addition of cenosphere alone reduces the mechanical strength of mortar; instead, the strength can be stabilized using silica fume as constant replacement in cement. The test results at 3 days strength show that the strength of SFCS5, SFCS10, SFCS15, SFCS20, SFCS25, and SFCS30 decreases by $5.71 \%, 8.57 \%, 14.29 \%, 20 \%, 22.86$, and $28.57 \%$ in comparison with SFCS0. The test results at 7 days strength show that the strength of SFCS5, SFCS10, SFCS15, SFCS20, SFCS25, and SFCS30 decreases by 7.37\%, 10.71\%, $12.95 \%, 20.20 \%, 22.99$, and $26.69 \%$ in comparison with SFCS0. The test results at 28 days strength show that the strength of SFCS5, SFCS10, SFCS15, SFCS20, SFCS25, and SFCS30 decreases by $4.36 \%, 5.57 \%, 10.10 \%, 15.85 \%, 18.29 \%$, and $20.03 \%$ in comparison with SFCS0.

It was noted that all the values of SFCS series are more than the required target strength which is required for a 43 Grade cement which has a value of $43 \mathrm{MPa}$, and the same pattern was observed on all ages. Also, it was noted that as the ages increase the strength variation with SFCS0 decreases, 
TABLE 2: Results on compressive strength of mortar cubes.

\begin{tabular}{|c|c|c|c|c|c|}
\hline \multirow{2}{*}{ S. Number } & \multirow{2}{*}{ Mix ID } & \multirow{2}{*}{$\%$ replacement of cenosphere to cement } & \multicolumn{3}{|c|}{ Compressive strength in $\mathrm{MPa}$} \\
\hline & & & 3 days & 7 days & 28 days \\
\hline 1 & SFCS0 & 0 & 35 & 45 & 57 \\
\hline 2 & SFCS5 & 5 & 33 & 42 & 55 \\
\hline 3 & SFCS10 & 10 & 32 & 40 & 54 \\
\hline 4 & SFCS15 & 15 & 30 & 39 & 52 \\
\hline 5 & SFCS20 & 20 & 28 & 36 & 48 \\
\hline 6 & SFCS25 & 25 & 27 & 35 & 47 \\
\hline 7 & SFCS30 & 30 & 25 & 32 & 46 \\
\hline
\end{tabular}

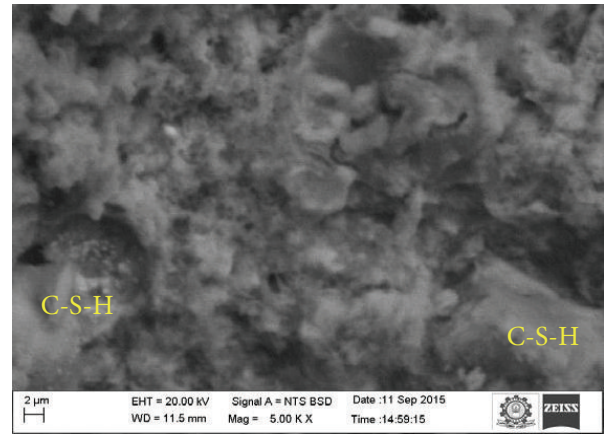

FIGURE 2: SEM image for SFCS0 specimen.

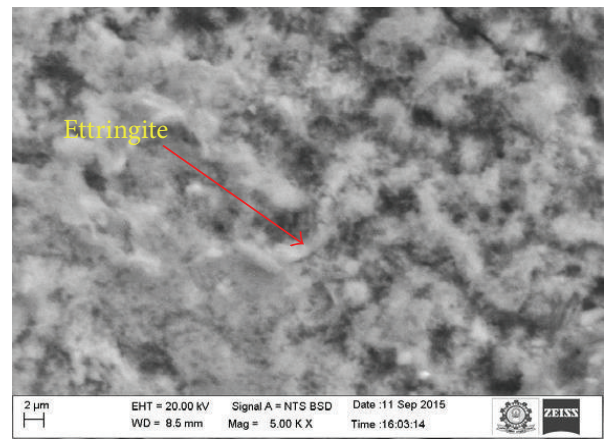

FIGURE 3: SEM image for SFCS5 specimen.

which shows that the active cenosphere content present in cement as replacement delays the strength attainment which may in turn reduces the microstructural cracks and their shrinkage. It has also been observed that the density gets reduced $[1,13]$.

3.2. SEM and XRD Analysis. Figure 2 shows the micrograph of SFCS0 specimen, and this shows the denseness of control specimen along with hydration products. The control specimen behaved as would have been predicted by literature. Considerable amount of calcium hydroxide formation was observed in the specimen. The SFCS5 micrograph was shown in Figure 3 which has clustered structure. The structure was due to the presence of alumina silicate in cenosphere and silica from silica fume. The formation of ettrignite was also observed [14]; this may be due to the reduction in hydration

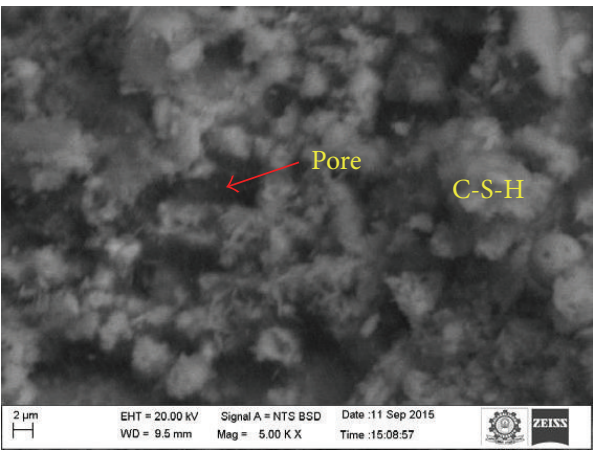

FIGURE 4: SEM image for SFCS10 specimen.

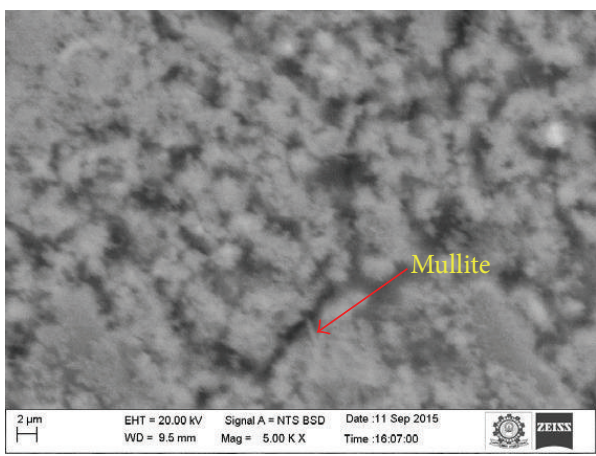

FIGURE 5: SEM image for SFCS15 specimen.

which can be substantiated by the earlier studies [15]. Figure 4 shows the SEM image of SFCS10 specimen, the disintegration is due to the consumption of calcium hydroxide due to the pozzolanic reaction and carbonation effect. But still the reaction of silica fume holds the structural integrity through its silicious effects [1]. Figure 5 shows the SEM image of SFCS15 specimen, and, from the observation, it is evident that the presence of mullite and aluminosilicate by the addition of cenosphere replaces the spaces created by the absence of portlandite $[16,17]$. Also, some microstructural cracks were identified through the image. Figure 6, SEM image for SFCS20, shows that the cenosphere starts to appear in abundance which is due to the higher percentage replacement of cenosphere. The traces of ettrignite were also observed 


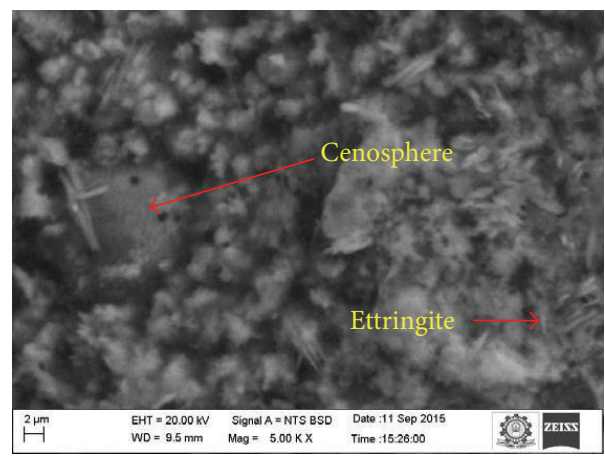

FIGURE 6: SEM image for SFCS20 specimen.

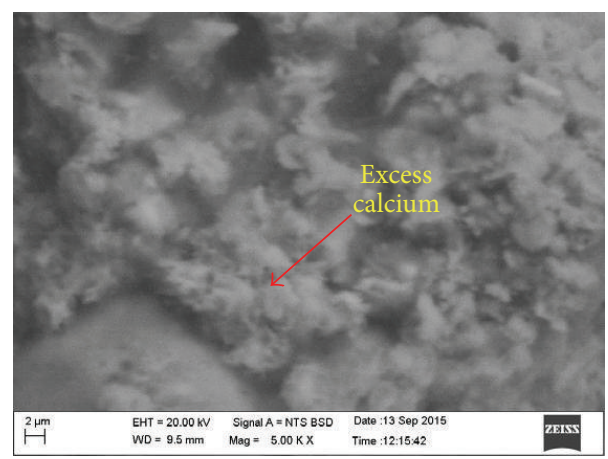

FIGURE 7: SEM image for SFCS25 specimen.

and it is substantiated by the XRD graph in Figure 9. The micrograph shows that the silica fume and cenosphere were well dispersed inside the structure and the bonding was maintained. Figure 7 shows the micrograph for the specimen SFCS25; the structure is disintegrated and it is due to the reaction of excess calcium from cenosphere over the pozzolanic products. The surface becomes cloggier and the abundance of cenosphere was also noted. The SEM image of SFCS30 is shown in Figure 8 and the microstructure is completely disintegrated and shows heavier cracks. Even the occurrence of hydration products was very low and was confirmed through the XRD graph in Figure 9. From all the observations of SEM images from Figures 2-8, it can be identified that the cenosphere has an effect on microstructural part of the cement mortars. The cenospheres behave initially as fillers, and, as the percentage of replacement increases, it reacts with the hydration materials causing the structure to become disintegrated and creation of microstructural cracks which in terms affects the strength and performance of the mortars. The cement pastes with higher replacement of cenospheres have tortuous and cracked patterns. The interaction shows the boundary layer separation between cenosphere and the cement paste and the crack passes through these regions. This separation is due to the less adhesion between the cenosphere and calcium hydroxides present in the paste. Most of the cracks go through the cenospheres which shows the energydissipating mechanism. Also, the cenosphere surfaces parted from cement materials showed less chemical reaction $[6,8]$.

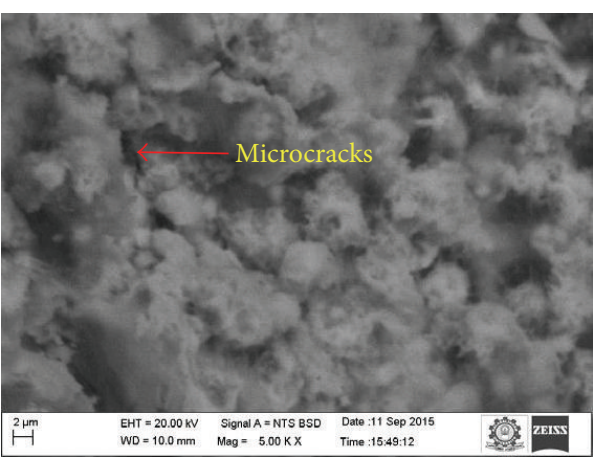

FIGURE 8: SEM image for SFCS30 specimen.

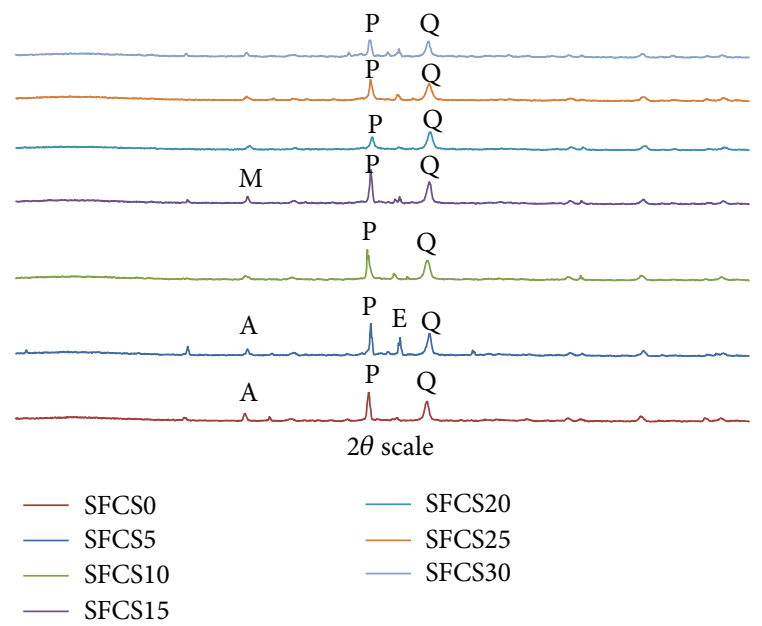

FIGURE 9: XRD analysis result in $2 \theta$ scale. P: portlandite; Q: quartz; A: aluminosilicate; E: ettrignite; M: mullite.

Figure 8 shows the results of XRD analysis. The excess alumina silicate in cenosphere attributed to the reduction in strength of the mortar. These alumina and silicate have effect on the pozzolanic reaction, hence forming void in the region of pozzolanic products. The abundance of mullite is also related to the percentage of replacement of cenosphere. The occurrence of portlandite reduces with increase in percentage of cenosphere and the trace of ettrignite is observed in specimens with higher percentage of cenosphere. The XRD results show that the addition of cenospheres improves the crystallization of hydration products. The chemical reaction between the cenosphere and hydration product was observed and this attributed to the decrease of portlandite and its formation [18]. And this results in the disintegrated microstructure. Thus, excessive addition of cenosphere may result in the inferior quality of cement mortars and reduced mechanical performance.

Thus, from the above studies, the cement mortar with replacement of cenosphere along with silica fume performs well with a reasonable amount of cenosphere; as the percentage of cenosphere increases, the strength starts to decrease; hence, it should be noted that the strength loss due to the addition of cenosphere should be well balanced by means of strength enhancing technique. 


\section{Conclusions}

This study demonstrated that mortar cubes can be produced with combination of cenosphere and silica fume as a replacement for cement. The test on mortar cubes revealed that cement losses its strength due to replacement of cenosphere, but the strength loss can be stabilized by adding silica fume. The specimens even though loss their strength and the strength limit falls within the safer limit and confirms required strength. The strength decrement reduces by ages, showing that the strength attainment is slowed by the addition of cenosphere. The microstructure was also studied and it shows the disintegrated structures on higher replacement of cenosphere. It was also noted that the hydration products react with cenospheres, and, due to this, reduction in quantity of portlandite was observed resulting in strength decrement.

\section{Competing Interests}

The authors declare that there are no competing interests regarding the publication of this paper.

\section{References}

[1] F. Blanco, P. García, P. Mateos, and J. Ayala, "Characteristics and properties of lightweight concrete manufactured with cenospheres," Cement and Concrete Research, vol. 30, no. 11, pp. 1715-1722, 2000.

[2] K. S. Chia, M. H. Zhang, and J. Y. R. Liew, "High-strength ultra lightweight cement composite-material properties," in Proceedings of the 9th International Symposium on High Performance Concrete-design, Verification and Utilization, Rotorua, New Zealand, August 2011.

[3] M. V. Deepthi, M. Sharma, R. R. N. Sailaja, P. Anantha, P. Sampathkumaran, and S. Seetharamu, "Mechanical and thermal characteristics of high density polyethylene-fly ash Cenospheres composites," Materials and Design, vol. 31, no. 4, pp. 2051-2060, 2010.

[4] S. Guhanathan, M. Saroja Devi, and V. Murugesan, "Effect of coupling agents on the mechanical properties of fly ash/polyester particulate composites," Journal of Applied Polymer Science, vol. 82, no. 7, pp. 1755-1760, 2001.

[5] S. Thongsang and N. Sombatsompop, "Effect of $\mathrm{NaOH}$ and Si69 treatments on the properties of fly ash/natural rubber composites," Polymer Composites, vol. 27, no. 1, pp. 30-40, 2006.

[6] J.-Y. Wang, M.-H. Zhang, W. Li, K.-S. Chia, and R. J. Y. Liew, "Stability of cenospheres in lightweight cement composites in terms of alkali-silica reaction," Cement and Concrete Research, vol. 42, no. 5, pp. 721-727, 2012.

[7] N. Barbare, A. Shukla, and A. Bose, "Uptake and loss of water in a cenosphere-concrete composite material," Cement and Concrete Research, vol. 33, no. 10, pp. 1681-1686, 2003.

[8] D. Montgomery and S. Diamond, "The influence of fly ash cenospheres on the details of cracking in flyash-bearing cement pastes," Cement and Concrete Research, vol. 14, no. 6, pp. 767775, 1984.

[9] P. R. Mudimela, L. I. Nasibulina, A. G. Nasibulin et al., "Synthesis of carbon nanotubes and nanofibers on silica and cement matrix materials," Journal of Nanomaterials, vol. 2009, Article ID 526128, 4 pages, 2009.
[10] J. K. Weng, B. W. Langen, and M. A. Ward, "Pozzolanic reaction in Portland cement, silica fume, and fly ash mixtures," Canadian Journal of Civil Engineering, vol. 24, no. 5, pp. 754-760, 1997.

[11] S. Koting, M. R. Karim, H. Mahmud et al., "Effects of using silica fume and polycarboxylate-type superplasticizer on physical properties of cementitious grout mixtures for semiflexible pavement surfacing," The Scientific World Journal, vol. 2014, Article ID 596364, 7 pages, 2014.

[12] K. Sudalaimani and M. Shanmugasundaram, "Influence of ultrafine natural steatite powder on setting time and strength development of cement," Advances in Materials Science and Engineering, vol. 2014, Article ID 532746, 6 pages, 2014.

[13] N. Barbare, A. Shukla, and A. Bose, "Uptake and loss of water in a cenosphere-concrete composite material," Cement and Concrete Research, vol. 33, no. 10, pp. 1681-1686, 2003.

[14] E. Scholtzová, L. Kucková, J. Kožíšek, and D. Tunega, "Structural and spectroscopic characterization of ettringite mineral combined DFT and experimental study," Journal of Molecular Structure, vol. 1100, Article ID 21641, pp. 215-224, 2015.

[15] V. Rahhal and R. Talero, "Very early age detection of ettringite from pozzolan origin," Construction and Building Materials, vol. 53, pp. 674-679, 2014.

[16] T. Sugama, N. R. Carciello, T. M. Nayberg, Unocal, and L. E. Brothers, "Mullite microsphere-filled lightweight calcium phosphate cement slurries for geothermal wells: setting and properties," Cement and Concrete Research, vol. 25, no. 6, pp. 1305-1310, 1995.

[17] S. Gomes and M. François, "Characterization of mullite in silicoaluminous fly ash by XRD, TEM, and ${ }^{29} \mathrm{Si}$ MAS NMR," Cement and Concrete Research, vol. 30, no. 2, pp. 175-181, 2000.

[18] V. Lilkov, N. Djabarov, G. Bechev, and O. Petrov, "Properties and hydration products of lightweight and expansive cements part II: hydration products," Cement and Concrete Research, vol. 29, no. 10, pp. 1641-1646, 1999. 

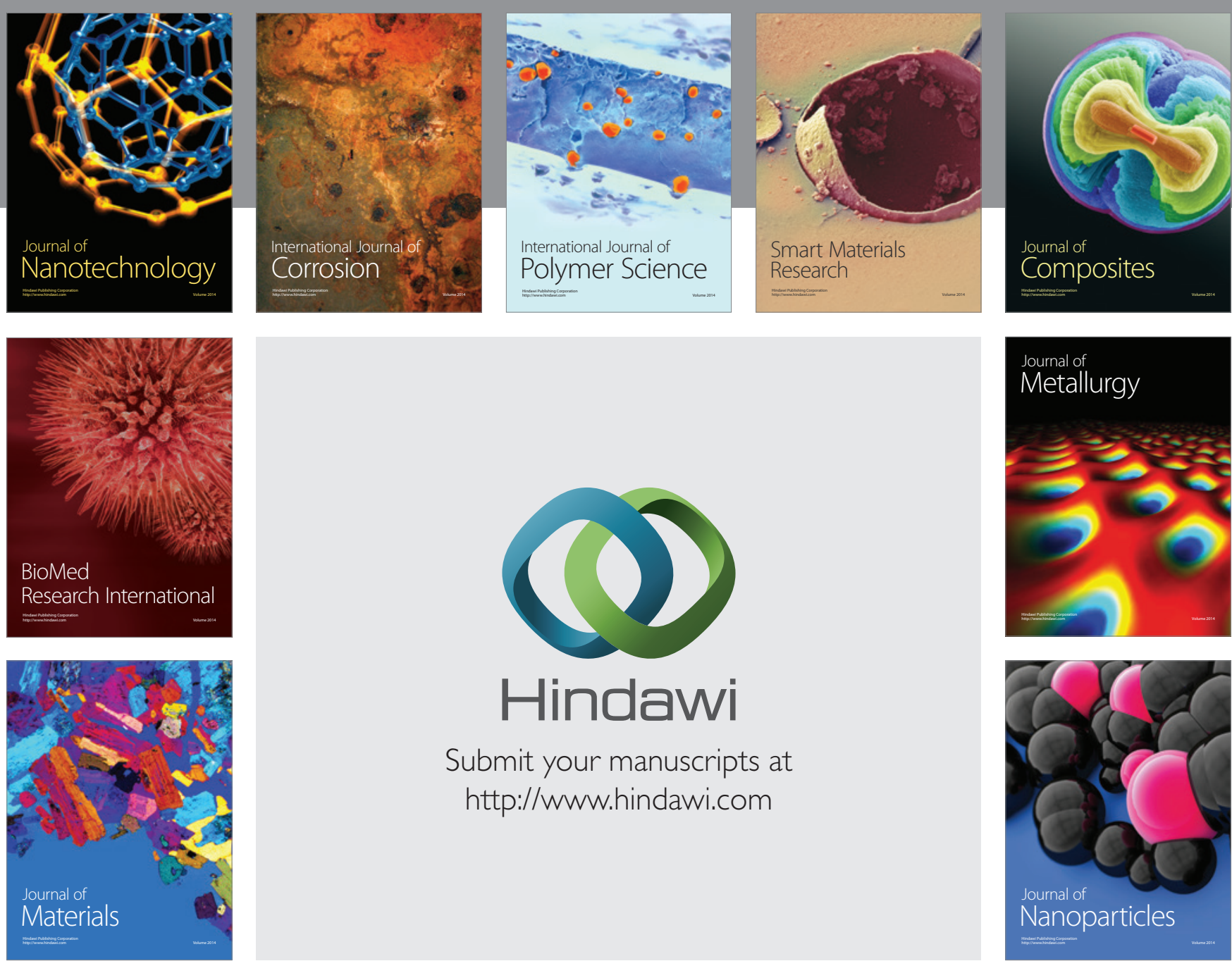

\section{Hindawi}

Submit your manuscripts at

http://www.hindawi.com

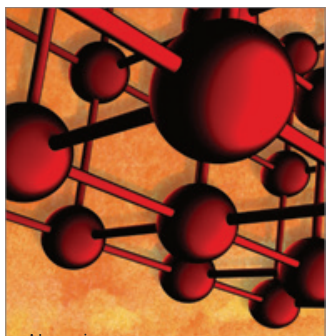

Materials Science and Engineering
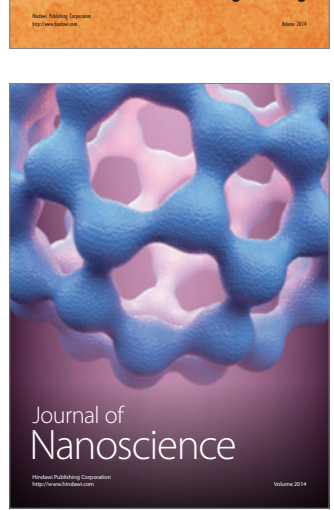
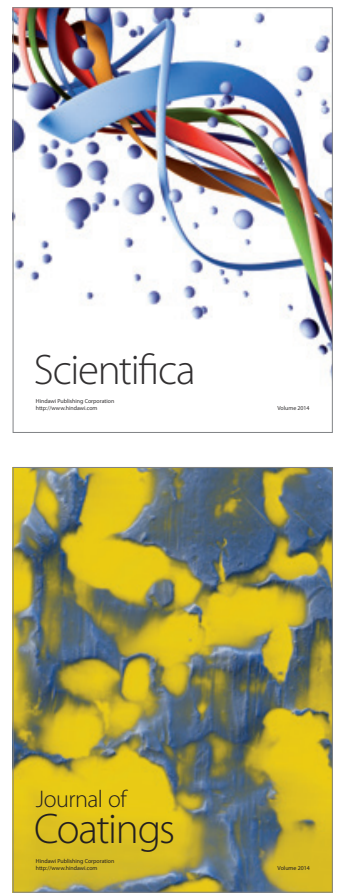
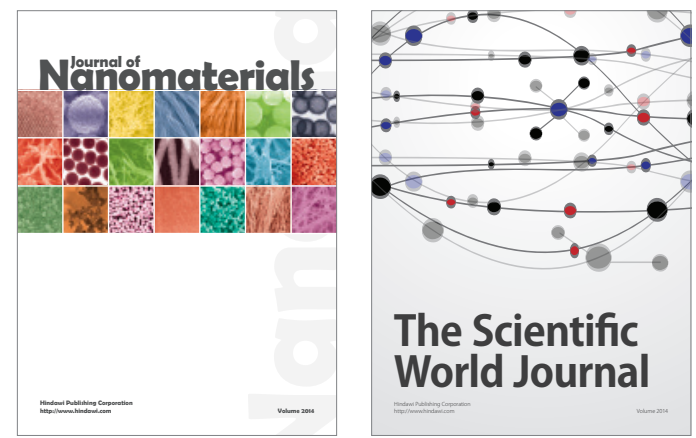

The Scientific World Journal
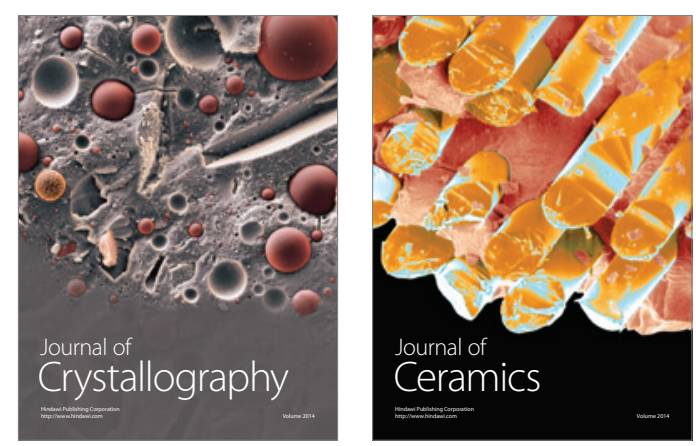
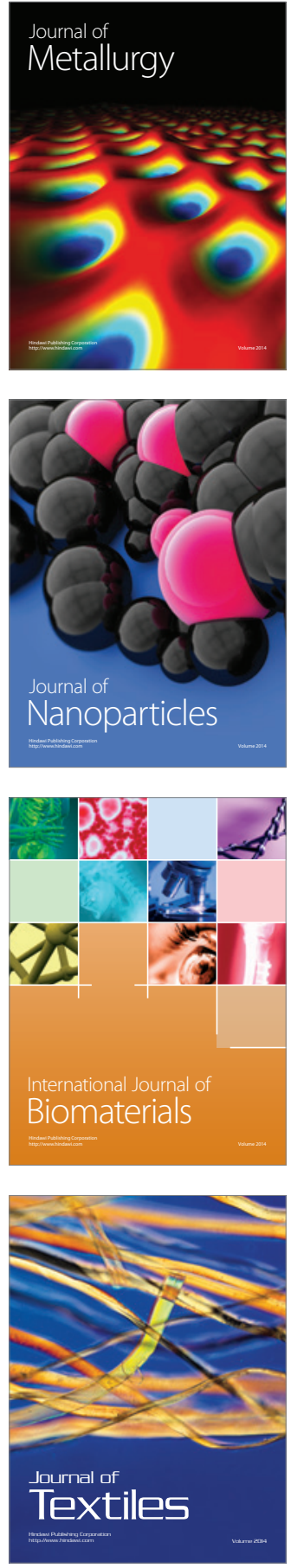